\title{
PENGARUH ETIKA KERJA ISLAM DAN ETIKA BISNIS TERHADAP KOMITMEN ORGANISASI DENGAN KOMITMEN PROFESI SEBAGAI VARIABEL INTERVENING
}

\author{
Leny Novianti \\ Universitas Islam Negeri Sultan Syarif Kasim Riau, email: lenynofianti@yahoo.com \\ Hendra Gunawan \\ Universitas Islam Bandung
}

\begin{abstract}
This research aims at examining the effect of variable of Islamic work ethics and business ethics on the organizational and professional commitment, in which variable of professional commitment functions as intervening variable. The primary data of this research are collected through collecting opinion or perception of external auditors, who fills in and submit quetionnaire to the researcher. The 30 copies of questionnaire distributed to the public accountant in Riau with sensu. Questionnaire are analyzed by using regression technique with help of SPSS $\vee 16$ program and multiple regression analysis. The result of this research shows that the more understand the external auditor the prevailed custom or rule of work, either in the profession ethics or Islamic work ethics and bussiness ethics the better he does his duty and function as external auditor. And furthermore, it has effect on his commitment of profession as a external auditor and commitment of organization.
\end{abstract}

Keywords: Islamic work ethics, business ethics, organizational commitment, professional commitment, external auditor, multiple regression

\section{PENDAHULUAN}

Di Indonesia, etika akuntan menjadi isu yang sangat menarik. Tanpa etika, profesi akuntansi tidak akan ada karena fungsi akuntansi adalah penyedia informasi untuk proses pembuatan keputusan bisnis oleh para pelaku bisnis. Disamping itu, profesi akuntansi mendapat sorotan yang cukup tajam dari masyarakat. Hal ini seiring dengan terjadinya beberapa pelanggaran etika yang dilakukan oleh akuntan, baik akuntan publik, akuntan intern perusahaan maupun akuntan pemerintah.

Setiap organisasi bertanggungjawab untuk berusaha mengembangkan suatu perilaku organisasi yang mencerminkan kejujuran dan etika yang dikomunikasikan secara tertulis dan 
dapat dijadikan pegangan oleh seluruh pegawai. Kultur tersebut harus memiliki akar dan memiliki nilai-nilai luhur yang menjadi dasar bagi etika pengelolaan suatu organisasi atau suatu entitas. Etika adalah refleksi kritis dan rasional mengenai nilai dan norma moral yang menentukan dan terwujud dalam sikap dan pola perilaku hidup manusia, baik secara pribadi maupun sebagai kelompok. (Burhanudin, 1997).

Dari berbagai kasus menggambarkan bagaimana perusahaan bersedia melakukan apa saja demi laba. Wajar bila ada kesimpulan, dalam bisnis, satu-satunya etika yang diperlukan hanya sikap baik dan sopan kepada pemegang saham. Harus diakui, kepentingan utama bisnis adalah menghasilkan keuntungan maksimal bagi shareholders. Fokus itu membuat perusahaan yang berpikiran pendek dengan segala cara berupaya melakukan hal-hal yang bisa meningkatkan keuntungan. Kompetisi semakin ketat dan konsumen yang kian rewel sering menjadi faktor pemicu perusahaan mengabaikan etika dalam berbisnis. Namun, belakangan beberapa akademisi dan praktisi bisnis melihat adanya hubungan sinergis antara etika dan laba. Menurut mereka, justru di era kompetisi yang ketat ini, reputasi baik merupakan sebuah competitive advantage yang sulit ditiru. Salah satu kasus yang sering dijadikan acuan adalah bagaimana Johnson \& Johnson (J\&J) menangani kasus keracunan Tylenol tahun 1982. Secara jangka panjang, filosofi J\&J yang meletakkan keselamatan konsumen di atas kepentingan perusahaan berbuah keuntungan lebih besar kepada 3 perusahaan.

Doug Lennick dan Fred Kiel, 2005 (dalam anderson, 2008) penulis buku Moral Intelligence, berargumen bahwa perusahaan-perusahaan yang memiliki pemimpin yang menerapkan standar etika dan moral yang tinggi terbukti lebih sukses dalam jangka panjang. Hal sama juga dikemukakan miliuner Jon M Huntsman, 2005 (dalam Anderson, 2008) dalam buku Winners Never Cheat. Dikatakan, kunci utama kesuksesan adalah reputasinya sebagai pengusaha yang memegang teguh integritas dan kepercayaan pihak lain. Berkaca pada beberapa contoh kasus itu, sudah saatnya kita merenungkan kembali cara pandang lama yang melihat etika dan bisnis sebagai dua hal berbeda. Memang beretika dalam bisnis tidak akan memberi keuntungan segera. Karena itu, para pengusaha dan praktisi bisnis harus belajar untuk berpikir jangka panjang. Peran masyarakat, terutama melalui pemerintah, badan-badan pengawasan, LSM, media, dan konsumen yang kritis amat dibutuhkan untuk membantu meningkatkan etika bisnis berbagai perusahaan di Indonesia.

Menurut Rahmi, 1993 (dalam gunawan, 2003), etika diterjemahkan menjadi kesusilaan karena sila berarti dasar, kaidah dan aturan, su berarti baik, benar dan bagus. Jadi yang dimaksud etika atau yang dapat disebut sebagai kaidah etik masyarakat adalah pedoman, 
patokan atau ukuran berperilaku yang tercipta melalui konsesus atau keagamaan atau kebiasaan yang didasarkan pada nilai baik dan buruk. Apabila terjadi pelanggaran maka sanksinya bersifat moral psikologik yaitu dikucilkan atau disingkirkan dari pergaulan masyarakat.

Dalam menjalankan pekerjaannya seorang eksternal auditor tidak terlepas dari adanya aturan etika profesi, yang di dalam prakteknya digunakan pedoman kode etik akuntan Indonesia. Kode etik Akuntan adalah norma perilaku yang mengatur hubungan antara akuntan publik dengan para klien, dengan sesama anggota profesi dan juga masyarakat. Selain itu kode etik akuntan juga merupakan alat atau sarana untuk memberikan keyakinan kepada para klien, pemakai laporan keuangan atau masyarakat pada umumnya tentang kualitas atau mutu jasa yang diberikannya. Oleh karena itu penelitian ini berusaha untuk menganalisis bagaimana pengaruh etika kerja Islam yang dianut oleh eksternal auditor dalam melaksanakan tugasnya, dan etika bisnis yang diterapkan dalam organisasi, yang selanjutnya mempengaruhi perilakunya baik komitmennya terhadap profesi maupun komitmennya terhadap organisasi. Jelas tanpa suatu etika yang menjadi acuan, para penguasa dan pebisnis akan lepas tidak terkendali, mengupayakan segala cara, mengorbankan apa saja untuk mencapai tujuannya. Akibatnya sungguh mengerikan. Mereka dapat menyebabkan perang antar bangsa, antar lembaga, atau antar perusahaan. Mereka menganggap dan membuat bisnis seperti medan perang. John Rodes menggambarkan mereka sebagai orang yang tidak alamiah, yang bahkan disamakan dengan monster yang sangat kejam.

Burhanudin (1996), mengungkapkan bahwa Etika Islam bersumber pada firman Allah SWT yang autentik, yaitu Al Qur'an, Hadits yang merupakan contoh-contoh dari kehidupan Nabi Muhammad SAW, ljma dan Qiyas. Bahwa hukum dan ketetapan etika itu dapat dijadikan pegangan dan pedoman hidup, itu hanya dapat diperoleh pada dasar-dasar moral yang ditetapkan oleh Allah SWT.

Menurut Triyuwono (2000), bahwa tujuan organisasi menurut Islam adalah menyebarkan rahmat pada semua mahluk. Tujuan itu secara normatif berasal dari keyakinan Islam dan misi hidup sejati manusia. Tujuan itu, pada hakekatnya bersifat transedental karena tujuan itu tidak hanya terbatas pada kehidupan dunia individu, tetapi pada kehidupan sesudah dunia ini (akherat). Dalam pencapaian tujuan tersebut diperlukan peraturan etik untuk memastikan bahwa upaya yang merealisasikan baik tujuan utama maupun tujuan operatif adalah di jalan yang benar. 
Diungkapkan Yousef (2000), bahwa Oliver (1990) menemukan etika kerja mempunyai hubungan signifikan dengan komitmen organisasi; Skas et.al., (1996) dalam gunawan (2003) menemukan bahwa keyakinan dalam etika kerja berhubungan langsung dengan komitmen organisasi, Putt et.al., (1989) dalam gunawan (2003) melaporkan bahwa etika kerja intrinsik lebih erat hubungannya dengan komitmen organisasi dibandingkan etika kerja pengukur global (global measure), atau ekstrinsik etika kerja; Morrow dan Mc Elroy (1986) dalam gunawan (2003) menegaskan bahwa terdapat hubungan yang positif antara etika kerja dengan komitmen organisasi.

Dari hal di atas perlu kiranya mengetahui pemahaman eksternal auditor terhadap permasalahan etika kerja dan etika bisnis, pada saat melaksanakan tugasnya sesuai dengan norma dan aturan yang berlaku, yang selanjutnya mempengaruhi komitmennya baik komitmennya terhadap profesi maupun komitmenya terhadap organisasi.

Alasan dilakukannya penelitian ini adalah karena pertama, bukti empiris pengaruh etika kerja Islam terhadap komitmen (profesi dan organisasi) di Indonesia yang mayoritas penduduknya beragama Islam masih sangat terbatas. Kedua, menindaklanjuti rekomendasi Gunawan Aji dan Arifin Sabeni (2003) untuk melakukan penelitian dengan menggunakan sampel yang berbeda dan pada kondisi dengan kultur yang berbeda guna memperkuat atau menyangkal temuan dari penelitiannya serta mengunakan. Ketiga, penelitian tentang etika kerja Islam yang berdasarkan Al Qur'an Surat Al Baqarah ayat 282 dikaitkan dengan etika bisnis di Indonesia belum pernah dilakukan sebelummya, sehingga akan memperkaya literatur akuntansi keperilakuan.

Rumusan Masalah

Sebagaimana penjelasan di atas bahwa etika merupakan permasalahan yang sangat berhubungan dengan moral dan moralitas dalam masyarakat di semua lingkungan masyarakat. Permasalah etika mungkin juga merupakan penyebab kegagalan dan keterpurukan moral bangsa ini. Fenomena-fenomena tersebut selanjutnya dirumuskan dalam bentuk identifikasi masalah sebagai berikut ;

1. Bagaimana pengaruh etika kerja Islam dan etika bisnis terhadap komitmen organisasi.

2. Bagaimana pengaruh etika kerja Islam dan etika bisnis terhadap komitmen profesi.

3. Bagaimana pengaruh etika kerja Islam dan etika bisnis terhadap komitmen organisasi melalui komitmen profesi. 


\section{LANDASAN TEORI DAN PENGEMBANGAN HIPOTESIS}

Etika Kerja Islam

Menurut Triyuwono (2000), bahwa tujuan organisasi menurut Islam adalah menyebarkan rahmat pada semua mahluk. Tujuan itu secara normatif berasal dari keyakinan Islam dan misi hidup sejati manusia. Tujuan itu, pada hakekatnya bersifat transedental karena tujuan itu tidak hanya terbatas pada kehidupan dunia individu, tetapi pada kehidupan sesudah dunia ini (akherat). Dalam pencapaian tujuan tersebut diperlukan peraturan etik untuk memastikan bahwa upaya yang merealisasikan baik tujuan utama maupun tujuan operatif adalah di jalan yang benar.

Diungkapkan juga oleh Triyuwono (2000), bahwa etika itu terekspresikan dalam bentuk syari'ah, yang terdiri dari Al Qur'an, Hadist, ljma dan Qiyas. Etika merupakan sistem hukum dan moralitas yang komprehensif meliputi seluruh wilayah kehidupan manusia. Didasarkan pada sifat keadilan, etika syari'ah bagi umat Islam berfungsi sebagai sumber serangkaian kriteria untuk membedakan mana yang benar (haq) dan mana yang buruk (batil). Menurut Cohen et.al. (1999), setiap tindakan individu pertama-tama ditentukan oleh kebutuhannya. Kebutuhan-kebutuhan tersebut, setelah berinteraksi dengan pengalaman-pengalaman pribadi dan sistem nilai individu, akan menentukan harapan-harapan atau tujuan-tujuan dalam setiap perilakunya, sebelum akhirnya individu tersebut menentukan tindakan apa yang akan dilakukan.

\section{Etika Bisnis}

Etika bisnis merupakan studi yang dikhususkan mengenai moral yang benar dan salah. Studi ini berkonsentrasi pada standar moral sebagaimana diterapkan dalam kebijakan, institusi, dan perilaku bisnis. Etika bisnis merupakan studi standar formal dan bagaimana standar itu diterapkan ke dalam system dan organisasi yang digunakan masyarakat modern untuk memproduksi dan mendistribusikan barang dan jasa dan diterapkan kepada orang-orang yang ada di dalam organisasi. Penelitian yang dikaitan dengan etika dilaporkan Ludigdo dan Machfoedz (1999) bahwa tidak ada perbedaan persepsi terhadap etika bisnis yang signifikan antara akuntan pendidik, akuntan publik, dan akuntan pendidik sekaligus akuntan publik. Akuntan publik cenderung mempunyai persepsi yang paling baik dibandingkan yang lainnya. Orientasi etis auditor diketahui Shaub et.al., (1993) mempengaruhi tidak hanya sensitivitas etisnya, tetapi juga komitmen yang lebih tinggi tidak menghasilkan auditor yang sensitif secara etis. 
Komitmen Profesional

Komitmen profesional mengacu pada kekuatan identifikasi individual dengan profesi. Individual dengan komitmen profesional yang tinggi dikarakterkan memiliki kepercayaan dan penerimaan yang tinggi dalam tujuan profesi, keinginan untuk berusaha sekuatnya atas nama profesi, dan keinginan yang kuat untuk mempertahankan keanggotaannya dalam profesi (Mowday et al., 1979). Secara khusus, komitmen organisasional yang tinggi seharusnya mendorong auditor ke perilaku yang sesuai dengan kepentingan publik dan menjauh dari perilaku yang membahayakan profesi.

Ponemon (1992) dalam Harsanti (2001) menyatakan bahwa komitmen profesi bisa dihasilkan dari proses akulturasi dan asimilasi pada saat masuk dan memilih untuk tetap dalam profesi yang bersangkutan dan juga menyimpulkan bahwa perilaku etik auditor berhubungan dengan tingginya komitmen auditor pada profesi. Dalam hal menjalankan profesi akan ada pertanggungjawaban tidak hanya pada pimpinan tetapi juga bertanggungjawab pada Allah, karena manusia hanya sekedar hamba-Nya dengan tujuan untuk mewujudkan keadilan sosio ekonomi di dunia dan di akherat (Burhanudin, 1997)

Komitmen Organisasi

Menurut Mowday, Porter dan Steers (1982) dalam Mas'ud (2002), komitmen didefinisikan sebagai 1) keinginan yang kuat untuk tetap menjadi anggota suatu organisasi, 2) kemauan untuk berusaha dengan semangat yang tinggi (kerja keras) demi organisasi, 3) kepercayaan, penerimaan terhadap nilai-nilai dan tujuan organisasi. Penelitian yang dikaitan dengan etika dilaporkan Ludigdo dan Machfoedz (1999) bahwa tidak ada perbedaan persepsi terhadap etika bisnis yang signifikan antara akuntan pendidik, akuntan publik, dan akuntan pendidik sekaligus akuntan publik. Akuntan publik cenderung mempunyai persepsi yang paling baik dibandingkan yang lainnya. Orientasi etis auditor diketahui Shaub et.al., (1993) mempengaruhi tidak hanya sensitivitas etisnya, tetapi juga komitmen yang lebih tinggi tidak menghasilkan auditor yang sensitif secara etis.

Dalam kehidupan berorganisasi dituntut adanya komitmen dari anggota-anggotanya. Islam mengatakan bahwa dalam setiap tindakan yang dilakukan oleh manusia akan diminta pertanggungjawaban baik di dunia maupun di akherat. Hipotesis yang diajukan pada penelitian ini adalah: 
H1: Etika kerja Islam dan etika bisnis mempunyai pengaruh positif terhadap komitmen organisasi.

H2: etika kerja Islam dan etika bisnis mempunyai pengaruh positif terhadap komitmen profesi.

H3: etika kerja Islam dan etika bisnis terhadap komitmen organisasi melalui komitmen profesi.

Kerangka Pemikiran Teoritis

Dari telaah teoritis yang mengembangkan hipotesis di muka, maka kerangka pemikiran teoritisnya sebagai berikut:

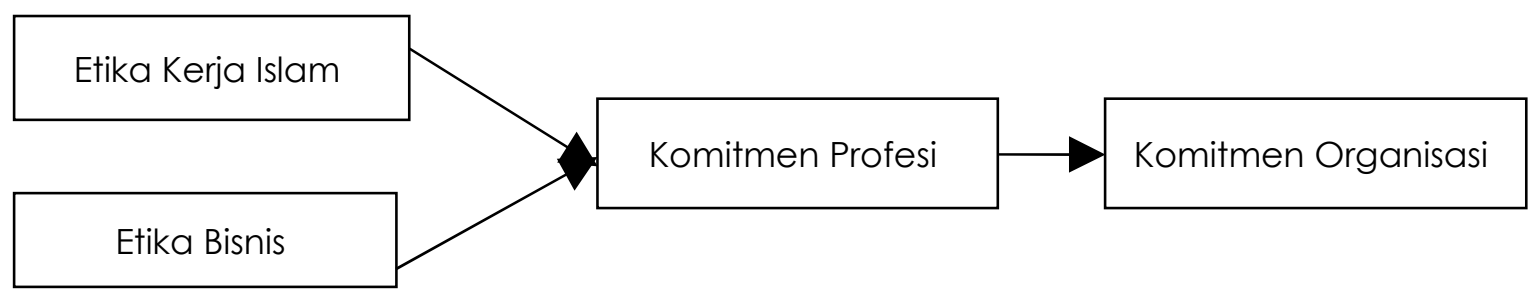

\section{METODE PENELITIAN}

Jenis data dalam penelitian ini adalah data subyek, yaitu jenis data yang berupa opini, sikap, pengalaman atau karakteristik dari seorang atau sekelompok orang yang menjadi subyek penelitian (responden) (Indriantoro dan Supomo, 1999). Sedangkan sumber data yang dipergunakan dalam penelitian ini adalah data primer. Data primer merupakan data penelitian yang diperoleh secara langsung dari sumber asli. (Indriantoro dan Supomo, 1999).

Populasi dalam penelitian ini adalah seluruh auditor yang bekerja pada Kantor Akuntan Publik (KAP) di Kota Pekanbaru. Karena jumlahnya hanya 30 orang, maka semua populasi akan menjadi sampel atau dengan kata lain sensus. Alasan auditor eksternal menjadi responden mengingat auditor merupakan aktivitas profesi yang memiliki sumber etika yang diatur dalam standar etika profesionalnya sehingga akan memiliki ukuran yang jelas. Selain itu auditor merupakan profesi yang independen dan beraktivitas melakukan pemeriksaan terhadap satuan aktivitas kliennya dengan skil, kompetensi yang berazaskan etika.

Data yang digunakan adalah data primer. Data penelitian ini dikumpulkan dengan cara mengantarkan langsung ke alamat responden, demikian pula pengembaliannya dijemput 
sendiri ke alamat responden sesuai dengan janji. Responden diharapkan mengembalikan kembali kuesioner ini kepada peneliti dalam waktu yang telah ditentukan

Operasionalisasi dan Pengukuran Variabel

Etika kerja Islam tersebut dijabarkan menjadi 3 dimensi sesuai pengertian dari surat Al Baqarah ayat 282 yang merupakan prinsip dasar akuntansi menurut Islam yaitu pertanggungjawaban, keadilan dan kebenaran (Muhammad, 2000). Berbeda dengan penelitian Gunawan dan Arifin (2003) sebelumnya, penelitian ini mengunakan instrumen yang dikembangkan oleh Yousef, Darwis A (2000) yang terdiri dari 17 item pertanyaan.

Etika bisnis diukur dengan mengunakan instrumen penelitian yang dikembangkan oleh Freble J.F dan A. Reichel (1988) yang telah dimodifikasi untuk keperluan penelitian ini terdiri dari 16 item pertanyaan.

Komitmen profesi di ukur dengan menggunakan 6 item skala komitmen profesi yang digunakan Aranya (1984) yang telah dimodifikasi untuk keperluan penelitian ini. Pengukuran komitmen profesi merepresentasikan individu pada etika profesi yang harus ditaati di samping etika keagamaan.

Komitmen organisasi diukur dengan menggunakan 6 item skala komitmen profesi yang digunakan Aranya (1984) yang telah dimodifikasi untuk keperluan penelitian ini. Pengukuran komitmen organisasi merepresentasikan loyalitas di mana individu secara psikologis mengindetifikasikan komitmennya pada organisasi tempat kerjanya

Statistik Deskriptif

Gambaran umum mengenai responden dijelaskan dengan tabel distribusi frekuensi yang menunjukkan pendidikan responden, lamanya bekerja di KAP dan umur responden. Sedangkan untuk memberikan deskripsi tentang karakter variabel penelitian etika kerja Islam, etika bisnis, komitmen profesi dan komitmen organisasi digunakan tabel distribusi frekuensi yang menunjukkan angka modus, kisaran skor dan standar deviasi

Menurut Hair et.al. (2006) kualitas data yang dihasilkan dari penggunaan instrumen penelitian dapat di evaluasi melalui uji reliabilitas dan validitas. Uji tersebut masing-masing untuk mengetahui konsitensi dan akurasi data yang dikumpulkan dari penggunaan instrumen. Ada 2 prosedur yang dilakukan untuk mengukur reliabilitas dan validitas data, 
yaitu : (1) Uji konsistensi internal dengan koefisien Cronbach Alpha, (2) Uji validitas konstruk dengan cara mengkorelasikan antara skor masing-masing item dan skor totalnya.

Uji Multikolinearitas dengan tujuan untuk menguji apakah model regresi ditemukan adanya korelasi antar variabel bebas (independen). Detekasi terhadap ada tidaknya multikolinearitas yaitu dengan menganalisis matriks korelasi variabel-variabel bebas, dapat juga dilihat dengan pada nilai tolerance serta nilai variance inflation factor (VIF). Uji Autokorelasi dilakukan untuk mengetahui apakah ada korelasi antara disturbance term dengan memperhatikan nilai Durbin Watson ( $d w$ ) pada analisis regresi. Uji heteroskedastisitas bertujuan menguji apakah dalam model regresi terjadi ketidaksamaan variance dari residual satu pengamatan ke pengamatan lain. Pengujian hipotesis dalam penelitian ini menggunakan analisis regresi berganda (multiple regression) dengan SPSS V.16

\section{HASIL DAN PEMBAHASAN}

Penyajian statistik deskriptif bertujuan agar dapat dilihat profil dari data penelitian tersebut dan hubungan antar variabel yang digunakan. Statistik deskriptif yang menggambarkan kondisi responden merupakan informasi tambahan untuk memahami hasil penelitian. Statistik deskriptif pertama adalah jenis kelamin, yang dapat dilihat sebagai berikut:

Tabel 1

Jenis Kelamin

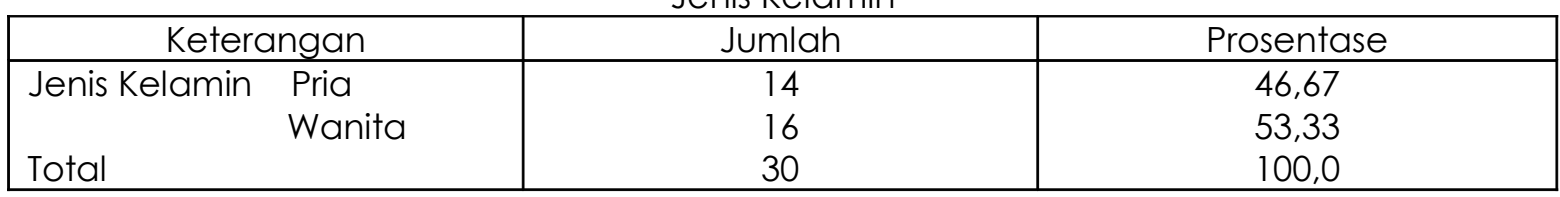

Jenis kelamin yang paling banyak adalah perempuan yaitu sebesar 16 orang atau $53,33 \%$ dan jenis kelamin perempuan sebanyak 14 orang atau $46,67 \%$.

Statistik deskriptif kedua adalah pendidikan responden, yang dapat dilihat sebagai berikut:

Tabel 2

Pendidikan

\begin{tabular}{|c|c|c|}
\hline Keterangan & Jumlah & Prosentase \\
\hline $\begin{array}{ll}\text { Pendidikan } & \text { S } 1 \\
& \text { S } 2 \\
\text { Total } & \end{array}$ & $\begin{array}{c}29 \\
1 \\
30\end{array}$ & $\begin{array}{c}96,67 \\
3,33 \\
100,0\end{array}$ \\
\hline
\end{tabular}

Dari tabel 2 terlihat bahwa sebagian besar responden berpendidikan S1 sebanyak 29 orang atau $96,67 \%$ kemudian $\$ 2$ sebanyak 1 orang atau $3,33 \%$ 
Dengan demikian berdasarkan lampiran 1, dapat diambil kesimpulan bahwa ke-17 item pernyataan yang berhubungan dengan Etika Kerja Islam (Variabel X1) dinyatakan valid. Berdasarkan lampiran 2 dapat dilihat bahwa ke-16 pernyataan yang berhubungan dengan Etika Bisnis (variabel X2) mempunyai hubungan yang signifikan. Hal tersebut berarti masingmasing item pertanyaan adalah Valid untuk mengukur Etika BisniS. Berdasarkan lampiran 3 dapat dilihat bahwa ke-18 pernyataan yang berhubungan dengan Komitmen Profesional (variabel Z) mempunyai hubungan yang signifikan. Hal tersebut berarti masing-masing item pertanyaan adalah Valid untuk mengukur Komitmen Profesional. Berdasarkan lampiran 4 dapat dilihat bahwa ke-11 pernyataan yang berhubungan dengan Komitmen Profesional (variabel Y) mempunyai hubungan yang signifikan. Hal tersebut berarti masing-masing item pertanyaan adalah Valid untuk mengukur Komitmen Organisasi .

Uji Reabilitas

Untuk memudahkan pengujian reliabilitas instrument tersebut, data diolah menggunakan program SPSS V.16 yang hasilnya sebagaimana ditunjukkan, maka tingkat reliabilitas masingmasing instrumen pengukur variabel adalah sebagai berikut:

Tabel 3

Tingkat Reliabilitas Variabel

\begin{tabular}{|c|l|c|c|c|}
\hline No & \multicolumn{1}{|c|}{ Variabel } & Nilai Alpha & Nilai Standar Alpha & Keterangan \\
\hline 1 & Variabel X1 & 0.572 & 0.087 & Reliabilitas sedang \\
\hline 2 & Variabel X2 & 0.569 & 0.093 & Reliabilitas sedang \\
\hline 3 & Variabel Z & 0.572 & 0.087 & Reliabilitas sedang \\
\hline 4 & Variabel Y & 0.505 & 0.087 & Reliabilitas sedang \\
\hline
\end{tabular}

Sumber : Diolah dari data primer

Dari hasil nilai alpha pada Tabel 4.9 di atas menunjukkan bahwa semua item pernyataan variabel penelitian menunjukkan status reliabel atau pernyataan tersebut handal. Persamaan regresi linier yang diperoleh melalui metode penaksiran OLS (Ordinary Leas† Squares) dapat dikatakan baik untuk menggambarkan hubungan fungsional sekelompok variable bebas terhadap variable tak bebas jika persamaan tersebut memenuhi asumsi regresi klasik. Asumsi yang dilihat adalah error mengikuti distribusi normal, bebas kolinearitas dan tidak terdapat heteroskedastis.

Pengujian normalitas data terhadap error/residu dilakukan untuk melihat apakah persamaan yang diperoleh memenuhi asumsi yang mensyaratkan error hasil taksiran model regresi berdistribusi normal. Hasil perhitungan uji normalitas menggunakan KolmogorovSmirnov Test yang diuji menggunakan statistic SPSS V 16 disajikan dalam table berikut: 
Tabel 4

Uji Normalitas untuk Etika Bisnis One-Sample Kolmogorov-Smirnov Test

\begin{tabular}{|ll|r|}
\hline & & \multicolumn{1}{|c|}{ X2 } \\
\hline N & & 30 \\
& & 46.3021 \\
Most Extreme Differences & Mean & 2.32462 \\
& Std. Deviation & .117 \\
& Positive & .109 \\
& Negative & -.117 \\
Kolmogorov-Smirnov $Z$ & & .639 \\
Asymp. Sig. (2-tailed) & & .809 \\
\hline
\end{tabular}

a Test distribution is Normal

b Calculated from data

Uji normalitas untuk Komitmen Profesional, dimana besarnya nilai Kolmogorov_Smirnov adalah 0,831 dan siginfikans pada 0,494. Hal ini berarti Ho diterima yang berarti data residual terdistribusi normal.

Tabel 5

Uji Normalitas untuk Komitmen Profesional dengan One-Sample Kolmogorov-Smirnov Test

\begin{tabular}{|ll|r|}
\hline & & \multicolumn{1}{|c|}{$\mathrm{Z}$} \\
\hline $\mathrm{N}$ & & 30 \\
Normal Parameters(a,b) & Mean & 73.6303 \\
& Std. Deviation & 3.18971 \\
Most Extreme Differences & Absolute & .152 \\
& Positive & .152 \\
& Negative & -.139 \\
Kolmogorov-Smirnov Z & & .831 \\
Asymp. Sig. (2-tailed) & .494 \\
\hline \multicolumn{2}{|c|}{ a Test distribution is Normal. } & \\
\hline
\end{tabular}

b Calculated from data.

Uji normalitas untuk Komitmen Organisasi, dimana besarnya nilai Kolmogorov_Smirnov adalah 0,764 dan signifikans pada 0,603 . Hal ini berarti Ho diterima yang berarti data residual terdistribusi normal, tampak pada tabel di bawah ini:

Tabel 6

Uji Normalitas untuk Komitmen Organisasi dengan One-Sample Kolmogorov-Smirnov Test

\begin{tabular}{|c|c|c|}
\hline & & $Y$ \\
\hline \multirow[t]{6}{*}{$N$} & & 30 \\
\hline & Mean & 35.5988 \\
\hline & Std. Deviation & 2.44746 \\
\hline & Absolute & 140 \\
\hline & Positive & .082 \\
\hline & Negative & -.140 \\
\hline \multicolumn{2}{|c|}{ Kolmogorov-Smirnov Z } & .764 \\
\hline \multicolumn{2}{|c|}{ Asymp. Sig. (2-tailed) } & .603 \\
\hline
\end{tabular}

a Test distribution is Normal.

b Calculated from data. 
Berdasarkan model persamaan masing-masing Variabel penelitian didapat nilai DurbinWatson yaitu sebagaimana tertera dalam table 5.5 sebagai berikut:

Tabel 7

Uji Auto Korelasi Durbin-Watson Masing-masing Variabel ( $n=30$ )

\begin{tabular}{|c|c|}
\hline Variable & Durbin Watson \\
\hline $\mathrm{X} 1$ & 0.587 \\
\hline $\mathrm{X} 2$ & 0.619 \\
\hline $\mathrm{Z}$ & 0.740 \\
\hline
\end{tabular}

Melihat nilai Durbin-Watson diatas maka dapat diketahui bahwa untuk masing-masing Variabel penelitian tidak terdapat autokorelasi. Ada tidaknya terjadi multikolinearitas dapat dilihat dari nilai VIF (Variance Inflation Factors). Nilai VIF yang kecil menunjukkan tidak adanya korelasi yang tinggi antar variable bebas dalam model regresi. Batasan nilai variable dikatakan berkolinearitas tinggi jika diperoleh nilai VIF untuk variable bebas lebih besar dari 10 (Mayers, 1993). Hasil perhitungan nilai VIF untuk variable bebas dalam model regresi pada penelitian ini menunjukkan angka yang lebih kecil dari 10, sehingga disimpulkan tidak terjadi kolinearitas yang tinggi antar variable bebas dalam persamaan regresi yang diperoleh.

Tabel 8 : Uji Multikolinearitas Coefficient

\begin{tabular}{|l|l|r|r|}
\hline Model & & \multicolumn{2}{|c|}{ Collinearity Statistics } \\
\hline & & Tolerance & VIF \\
\hline 1 & (Constant) & & \\
& X1 & .969 & 1.032 \\
& X2 & .994 & 1.006 \\
& Z & .974 & 1.026 \\
\hline
\end{tabular}

Heteroskedastis merupakan indikasi bahwa varian antar residu hasil model regresi yang diperoleh tidak homogen, yang mengakibatkan nilai taksiran yang diperoleh efisien. Untuk menguji apakah varian dari residual homogen digunakan pendekatan Uji Scatterplots.

Berdasarkan hasil SPSS yang disajikan dalam table dibawah ini, diketahui bahwa koefisien parameter untuk variable independent tidak ada yang signifikan, maka dapat disimpulkan bahwa model regresi tidak terdapat Heteroskedastis atau memiliki varians yang sama (homoskedastis). Hal ini konsisten dengan hasil uji Scatterplots sebagaimana di sajikan dalam tabel berikut: 
Tabel 9

Uji Heteroskedastis Variabel Penelitian

Coefficients(a), Collinearity Diagnostics(a)

\begin{tabular}{|r|l|r|r|r|r|r|r|}
\hline Model & Dimension & Eigenvalue & Condition Index & \multicolumn{4}{|c|}{ Variance Proportions } \\
\hline & & & & (Constant) & X1 & \multicolumn{1}{c|}{ X2 } & Z \\
\hline 1 & 1 & 3.995 & 1.000 & .00 & .00 & .00 & .00 \\
& 2 & .002 & 41.313 & .00 & .29 & .66 & .06 \\
& 3 & .002 & .001 & .01 & .57 & .05 & .50 \\
& 4 & .001 & 80.003 & .99 & .14 & .29 & .44 \\
\hline
\end{tabular}

a Dependent Variable: $Y$

Hasil pengujian pengaruh etika kerja Islam dan etika bisnis terhadap komitmen organisasi.

Tabel 10

Hasil regresi a

\begin{tabular}{|l|r|r|r|r|}
\hline Model & R & R Square & Adjusted R Square & Std. Error of the Estimate \\
\hline 1 & $.228(a)$ & .052 & -.018 & 2.46962 \\
\hline
\end{tabular}

a (Constant), $\times 2, \times 1$

b Dependent Variable: $Y$

Menunjukkan bahwa secara simultan pengaruh Etika Kerja Islam dan Etika Bisnis terhadap Komitmen Organisasi menunjukkan pengaruh sebesar 0,052 pengaruh ini sangat kecil. Sementara pengaruh secara parsial terlihat pada tabal berikut:

Tabel 11

Hasil regresi b

\begin{tabular}{|r|r|r|r|r|r|r|}
\hline Model & & \multicolumn{2}{|c|}{ Unstandardized Coefficients } & Standardized Coefficients & \multicolumn{1}{c|}{ Sig. } \\
\hline & & \multicolumn{1}{|c|}{ B } & Std. Error & Beta & & \\
\hline 1 & (Constant) & 50.480 & 12.395 & & 4.073 & .000 \\
& X1 & .084 & .126 & .125 & .667 & .011 \\
& X2 & .191 & .198 & .182 & .966 & .043 \\
\hline
\end{tabular}

Pengaruh Etika kerja Islam terhadap Komitmen organisasi sebesar 0.084 dengan pengaruh yang signifikan dimana nilai $\dagger$ sebesar 0.667 lebih besar dibandingkan nilai sig sebesar 0.1 1, sedangkan pengaruh etika bisnis terhadap komitmen organisasi menunjukkan angka 0.191 juga pengaruh ini signifikan dimana $\dagger$ uji lebih besar dibandingkan dengan nilai signifikansinya yaitu sebesar 0.043. Pengaruh Etika Kerja Islam dan Etika Bisnis Terhadap Komitmen Profesional. Hasil Pengujian dengan menggunakan alat bantu SPSS $\vee 16$ sebagaimana table di bawah ini.

Tabel 12

Hasil regresi $\mathrm{C}$

\begin{tabular}{|l|l|ll|}
\hline Model & $R$ & R Square & .026 \\
\hline 1 & $.160(a)$ & & \\
\hline
\end{tabular}

a Predictors: (Constant), X2, X1

b Dependent Variable: $Z$ 
Dari table 12 menunjukkan bahwa secara simultan pengaruh Etika Kerja Islam dan Etika Bisnis terhadap Komitmen Profesional menunjukkan pengaruh sebesar 0,026 pengaruh ini sangat kecil. Sementara pengaruh secara parsial terlihat pada tabel berikut:

Tabel 13

Hasil regresi d

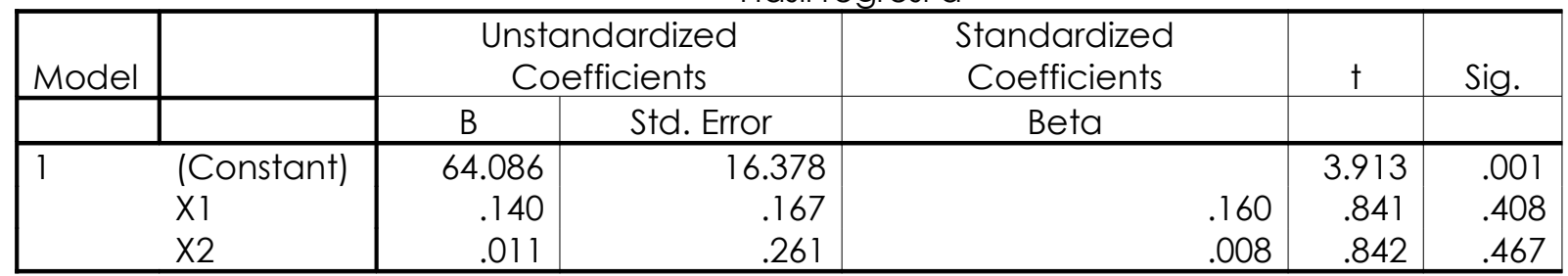

a Dependent Variable: $\mathrm{Z}$

Pengaruh Etika kerja Islam terhadap Komitmen Profesional adalah sebesar 0.140 dengan pengaruh yang signifikan dimana nilai $\dagger$ sebesar 0.841 lebih besar dibandingkan nilai sig sebesar 0.408, sedangkan pengaruh etika bisnis terhadap komitmen Profesional menunjukkan angka 0.011 juga pengaruh ini signifikan dimana † uji lebih besar dibandingkan dengan nilai signya yaitu sebesar 0.467. Hal ini sesuai dengan penelitian Finn et. al (1988) dalam Harsanti (2001), Nasron (2002)dan Gunawan dan Arifin (2003) untuk pengaruh etika kerja Islam terhadap komitmen Profesional menemukan bahwa akuntan yang bersedia mempertahankan standar ideal profesi menunjukkan tingkat komitmen profesi yang tinggi. Pengaruh Etika Kerja Islam dan Etika Bisnis melalui Komitmen Profesional terhadap Komitmen Organisasi. Pengaruh komitmen profesional terhadap komitmen organisasional tampak pada tabel di bawah ini:

Tabel 14

Hasil regresi e

\begin{tabular}{|l|r|r|r|}
\hline Model & R & R Square & Adjusted R Square \\
\hline 1 & $.562(\mathrm{a})$ & .316 & .291 \\
\hline
\end{tabular}

a Predictors: (Constant), $\mathrm{Z}$

b Dependent Variable: $Y$

output SPSS ini menunjukkan bahwa pengaruh Komitmen Profesional terhadap Komitmen Organisasi menunjukkan angka sebesar 0.316. Besaran pengaruh simultan variable penelitian ini adalah pengaruh gabungan langsung variable independen terhadap variable dependen melalui intervening variable, dengan demikian dapat dilakukan kalkulasi sebagai berikut:

$\begin{array}{ll}\text { Pengaruh } X 1 \text { terhadap } & Y=0.084 \\ \text { Pengaruh } X 2 \text { terhadap } & Y=0.191 \\ \text { Pengaruh } Z \text { terhadap } & Y=0.316 \\ \text { Pengaruh total } X 1, X 2, Z \text { terhadap } & Y=0.691\end{array}$


Dengan demikian etika kerja islam dan etika bisnis dalam mempengaruhi komitmen organisasi sangat tergantung pada komitmen professional hal ini terlihat bahwa pengaruh gabungan langsung etika kerja islam dan etika bisnis terhadap komitmen organisasi sebesar 0.052 berubah total setelah adanya factor intervening yaitu komitmen professional yang secara jumlah perubahan sangat besar yaitu menjadi 0.691. maka di kalangan Auditor eksternal di Kota Pekanbaru dalam menjalankan etika kerja islam dan etika bisnis perlu dilandasi oleh profesionalisme sehingga organisasi akuntan publik akan mengalami perkembangan yang baik. Hasil ini konsiten dengan penelitian Shaub et al (1993), Khomsiyah \& Indriantoro (1998), Harsanti (2001), Nasron (2002) dan Gunawan \& arifin (2003) untuk pengujian etika kerja Islam terhadap komitmen organisasi melalui komitmen profesional.

\section{SIMPULAN}

Berdasarkan hasil analisis data yang terkumpul dalam penelitian ini menunjukkan bahwa secara umum etika kerja kerja Islam dan etika bisnis berpengaruh positif terhadap komitmen profesinya dengan tingkat signifikansi probabilitasnya ( $p=0,000$ ) dibawah 0,05 dan juga berpengaruh terhadap positif komitmen organisasi dengan tingkat signifikansi probabilitasnya $(p=0,000)$ dibawah 0,05 . Demikian juga halnya dengan pengaruh antara etika kerja Islam dan etika bisnis terhadap komitmen organisasi melalui komitmen profesi menunjukkan adanya pengaruh positif signifikansi probabilitasnya $(p=0,000)$ dibawah 0,05 .

Hasil penelitian ini secara keseluruhan menunjukkan bahwa eksternal auditor yang semakin memahami norma atau aturan yang berlaku dalam hal ini baik kode etik dalam etika kerja Islam yang bersumber pada syariah dan etika binis, akan benar-benar melakukan tugas dan fungsinya sebagai seorang eksternal auditor, dan selanjutnya mempengaruhi komitmennya terhadap profesinya sebagai seorang eksternal auditor dan komitmennya terhadap organisasi. Dengan kata lain semakin tinggi pelaksanaan kode etik dalam etika kerja Islam secara menyeluruh dan menerapkan etika bisnis mencerminkan semakin tinggi pula adanya komitmen profesi eksternal auditor dan juga komitmennya terhadap organisasi.

\section{Keterbatasan}

Penelitian ini memiliki beberapa keterbatasan yang mungkin dapat menimbulkan gangguan terhadap hasil penelitian yang perlu dipertimbangkan. (1) cakupan penelitian ini dibatasi oleh ukuran sampel, hanya eksternal auditor yang ada di Pekanbaru sebagai rerangka sampling akan mempengaruhi hasil penelitian, dan bahkan mungkin kurang dapat 
digeneralisir. (2) pengukuran sikap skala likert yang disampaikan secara tertulis melalui kuesioner mungkin juga menghasilkan respon bias dan mempengaruhi validitas internal.

\section{DAFTAR REFERENSI}

Anderson Guntur Komenaung. 2008. Etika Bisnis. Dalam Website Google: Etika Dalam Bisnis Aranya, N., and KR Ferris. 1984. "Reexamination of Accountan Organizational Profesional Conflict ". The Accounting Review. Vol. 59 No. 1 pp. 1-12

Burhanudin Salam. 1997. "Etika Sosial, Asas Moral dalam Kehidupan Manusia", Edisi Pertama, Penerbit Rineka Cipta, Jakarta

Cohen, Aaron. 1999. Realtionship Among Five Forms of Commitment an Empirical Assessment, "Journal of Organizational Behavioral". Vol. 20, hal 283-308

Freble,J.F. and A. Reichel (1988), "Attitute towards business ethics of future Managers in the US and Israel", Journal of Business Ethics 7,pp 941-949

Fuad Mas'ud. 2002. 40 Mitos Manajemen Sumber Daya Manusia. Badan Penerbit Universitas Diponegoro Semarang

Gunawan, A. dan Sabeni, A. (2003). "Pengaruh Etika Kerja Islam Terhadap Komitmen Organisasi dengan Komitmen Profesi Sebagai Variabel Intervening (Studi Empiris Terhadap Internal Auditor Bank di Jawa Tengah)".Proceeding Simposium Nasional Akuntansi VI. Surabaya.

Hair, J.F., Black, William C. Babin, Barry J. Anderson, Rolph E. Tatham, \& Ronald L. 2006. "Multivariate Data Analysis" 6th ed. Upper Saddle River, Prentice Hall International, Inc.

Iwan Triyuwono. 2000. Organisasi dan Akuntansi Syari'ah. LKIS. Yogyakarta

Khomsiyah dan Nur Indriantoro. 1997. "Pengaruh orientasi etika terhadap komitmen dan sensitivitas etika auditor pemerintah di DKI Jakarta" Simposium Nasional Akuntansu $\backslash i$ (SNA) I

Ludigdo, Unti dan Mas'ud Machfoedz. 1999. "Persepsi Akuntan dan Mahasiswa terhadap Etika Bisnis". Journal Riset Akuntansi Indonesia. IAI. Vol. 2 No. 1 Januari. pp. 1-19

Muhammad dan R. Lukman Fauroni. 2002. Visi Al Qur'an tentang Etika dan Bisnis Penerbit Salemba Diniyah. Jakarta

Meyer, John P., Nathalie J. Allen, and Chaterine A. Smith. 1993. "Commitment to Organizations and Occupation : Extension and Test of Three Component Conceptualization". Journal of Applied Psychology. Vol. 78. No. 4. pp : 538-551.

Nasron Alfianto.,2002. Pengaruh Etika Kerja Akuntan terhadap Komitmen Profesi dan Komitmen Organisasi. Tesis Program Pasca Sarjana Magister Sains Akuntansi Universitas Diponegoro (tidak dipublikasikan) 
Nur Indriantoro, dan Bambang Supomo.1999. Metodologi Penelitian Bisnis. Edisi Pertama BPFE. Yogyakarta

Ponny Harsanti. 2001. "Studi Empiris tentang faktor-faktor yang mempengaruhi sensitivitas etika akuntan publikdi Indonesia", Thesis S-2, Program Pasca Sarjana, UNDIP Semarang (tidak dipublikasikan)

Shaub, Michael K., Don W. Finn and Paul Munter. 1993. "The effect of Auditors' Ethical Orientation on Commitment and Ethical Sensitivity ". Behavioral Research in Accounting. Vol. 5. pp : 145-169

Yousef, Darwish A. 2000. "Organizational Commitment as a Mediator of The Relationship between Islamic Work Ethics and Attitudes toward Organizational Change". Human Relations. Vol. 53 (4) : 513-537 
Lampiran 1

Hasil Uji Validitas Mengenai Etika Kerja Islam(Variabel X1) Pada Tingkat Signifikan 5\%

\begin{tabular}{|c|c|c|l|c|}
\hline Pertanyaan & rs Hitung & Angka Banding (Sig) & Kriteria Uji & Status \\
\hline 1 & 0.628 & 0.000 & rs hitung > Angka Banding (Sig) & Valid \\
\hline 2 & 0.720 & 0.000 & rs hitung > Angka Banding (Sig) & Valid \\
\hline 3 & 0.686 & 0.000 & rs hitung > Angka Banding (Sig) & Valid \\
\hline 4 & 0.492 & 0.006 & rs hitung > Angka Banding (Sig) & Valid \\
\hline 5 & 0.573 & 0.061 & rs hitung > Angka Banding (Sig) & Valid \\
\hline 6 & 0.617 & 0.000 & rs hitung > Angka Banding (Sig) & Valid \\
\hline 7 & 0.579 & 0.001 & rs hitung > Angka Banding (Sig) & Valid \\
\hline 8 & 0.832 & 0.000 & rs hitung > Angka Banding (Sig) & Valid \\
\hline 9 & 0.205 & 0.078 & rs hitung > Angka Banding (Sig) & Valid \\
\hline 10 & 0.409 & 0.025 & rs hitung > Angka Banding (Sig) & Valid \\
\hline 11 & 0.458 & 0.011 & rs hitung > Angka Banding (Sig) & Valid \\
\hline 12 & 0.832 & 0.000 & rs hitung > Angka Banding (Sig) & Valid \\
\hline 13 & 0.412 & 0.024 & rs hitung > Angka Banding (Sig) & Valid \\
\hline 14 & 0.745 & 0.000 & rs hitung > Angka Banding (Sig) & Valid \\
\hline 15 & 0.812 & 0.000 & rs hitung > Angka Banding (Sig) & Valid \\
\hline 16 & 0.743 & 0.000 & rs hitung > Angka Banding (Sig) & Valid \\
\hline 17 & 0.247 & 0.189 & rs hitung > Angka Banding (Sig) & Valid \\
\hline
\end{tabular}

Sumber : Diolah dari data primer

Lampiran 2

Hasil Uji Validitas Mengenai Etika Bisnis (Variabel X2) Pada Tingkat Signifikan 5\%

\begin{tabular}{|c|c|c|l|c|}
\hline Pertanyaan & rs Hitung & Angka Banding (Sig) & Kriteria Uji & Status \\
\hline 1 & 0.552 & 0.002 & rs hitung > Angka Banding (Sig) & Valid \\
\hline 2 & 0.554 & 0.005 & rs hitung > Angka Banding (Sig) & Valid \\
\hline 3 & 0.544 & 0.002 & rs hitung > Angka Banding (Sig) & Valid \\
\hline 4 & 0.309 & 0.097 & rs hitung > Angka Banding (Sig) & Valid \\
\hline 5 & 0.609 & 0.006 & rs hitung > Angka Banding (Sig) & Valid \\
\hline 6 & 0.322 & 0.003 & rs hitung > Angka Banding (Sig) & Valid \\
\hline 7 & 0.259 & 0.008 & rs hitung > Angka Banding (Sig) & Valid \\
\hline 8 & 0.776 & 0.000 & rs hitung > Angka Banding (Sig) & Valid \\
\hline 9 & 0.584 & 0.001 & rs hitung > Angka Banding (Sig) & Valid \\
\hline 10 & 0.586 & 0.014 & rs hitung > Angka Banding (Sig) & Valid \\
\hline 11 & 0.443 & 0.014 & rs hitung > Angka Banding (Sig) & Valid \\
\hline 12 & 0.551 & 0.008 & rs hitung > Angka Banding (Sig) & Valid \\
\hline 13 & 0.772 & 0.007 & rs hitung > Angka Banding (Sig) & Valid \\
\hline 14 & 0.292 & 0.007 & rs hitung > Angka Banding (Sig) & Valid \\
\hline 15 & 0.787 & 0.009 & rs hitung > Angka Banding (Sig) & Valid \\
\hline 16 & 0.218 & 0.006 & rs hitung > Angka Banding (Sig) & Valid \\
\hline
\end{tabular}

Sumber : Diolah dari data primer 
Lampiran 3

Hasil Uji Validitas Mengenai Komitmen Profesional (Variabel Z) Pada Tingkat Signifikan 5\%

\begin{tabular}{|c|c|c|l|c|}
\hline Pertanyaan & rs Hitung & Angka Banding (Sig) & \multicolumn{1}{|c|}{ Kriteria Uji } & Status \\
\hline 1 & 0.772 & 0.000 & rs hitung > Angka Banding (Sig) & Valid \\
\hline 2 & 0.597 & 0.001 & rs hitung > Angka Banding (Sig) & Valid \\
\hline 3 & 0.774 & 0.009 & rs hitung > Angka Banding (Sig) & Valid \\
\hline 4 & 0.661 & 0.025 & rs hitung > Angka Banding (Sig) & Valid \\
\hline 5 & 0.620 & 0.002 & rs hitung > Angka Banding (Sig) & Valid \\
\hline 6 & 0.423 & 0.020 & rs hitung > Angka Banding (Sig) & Valid \\
\hline 7 & 0.535 & 0.002 & rs hitung > Angka Banding (Sig) & Valid \\
\hline 8 & 0.565 & 0.001 & rs hitung > Angka Banding (Sig) & Valid \\
\hline 9 & 0.713 & 0.005 & rs hitung > Angka Banding (Sig) & Valid \\
\hline 10 & 0.528 & 0.003 & rs hitung > Angka Banding (Sig) & Valid \\
\hline 11 & 0.444 & 0.014 & rs hitung > Angka Banding (Sig) & Valid \\
\hline 12 & 0.627 & 0.086 & rs hitung > Angka Banding (Sig) & Valid \\
\hline 13 & 0.677 & 0.002 & rs hitung > Angka Banding (Sig) & Valid \\
\hline 14 & 0.448 & 0.013 & rs hitung > Angka Banding (Sig) & Valid \\
\hline 15 & 0.446 & 0.013 & rs hitung > Angka Banding (Sig) & Valid \\
\hline 16 & 0.680 & 0.002 & rs hitung > Angka Banding (Sig) & Valid \\
\hline 17 & 0.552 & 0.007 & rs hitung > Angka Banding (Sig) & Valid \\
\hline 18 & 0.629 & 0.008 & rs hitung > Angka Banding (Sig) & Valid \\
\hline
\end{tabular}

Sumber : Diolah dari data primer

Lampiran 4

Hasil Uji Validitas Mengenai Komitmen Organisasi (Variabel Y) Pada Tingkat Signifikan 5\%

\begin{tabular}{|c|c|c|l|c|}
\hline Pertanyaan & rs Hitung & Angka Banding (Sig) & Kriteria Uji & Status \\
\hline 1 & 0.654 & 0.015 & rs hitung > Angka Banding (Sig) & Valid \\
\hline 2 & 0.660 & 0.003 & rs hitung > Angka Banding (Sig) & Valid \\
\hline 3 & 0.414 & 0.023 & rs hitung > Angka Banding (Sig) & Valid \\
\hline 4 & 0.679 & 0.018 & rs hitung > Angka Banding (Sig) & Valid \\
\hline 5 & 0.550 & 0.030 & rs hitung > Angka Banding (Sig) & Valid \\
\hline 6 & 0.814 & 0.000 & rs hitung > Angka Banding (Sig) & Valid \\
\hline 7 & 0.672 & 0.022 & rs hitung > Angka Banding (Sig) & Valid \\
\hline 8 & 0.410 & 0.025 & rs hitung > Angka Banding (Sig) & Valid \\
\hline 9 & 0.581 & 0.001 & rs hitung > Angka Banding (Sig) & Valid \\
\hline 10 & 0.450 & 0.013 & rs hitung > Angka Banding (Sig) & Valid \\
\hline 11 & 0.206 & 0.015 & rs hitung > Angka Banding (Sig) & Valid \\
\hline
\end{tabular}

Sumber : Diolah dari data primer 